\title{
Decadal solar effects on temperature and ozone in the tropical stratosphere
}

\author{
S. Fadnavis and G. Beig \\ Indian Institute of Tropical Meteorology, Dr. Homi Bhabha Road, Pashan, Pune, 411008, India \\ Received: 9 December 2005 - Revised: 4 July 2006 - Accepted: 6 July 2006 - Published: 13 September 2006
}

\begin{abstract}
To investigate the effects of decadal solar variability on ozone and temperature in the tropical stratosphere, along with interconnections to other features of the middle atmosphere, simultaneous data obtained from the Halogen Occultation Experiment (HALOE) aboard the Upper Atmospheric Research Satellite (UARS) and the Stratospheric Aerosol and Gas Experiment II (SAGE II) aboard the Earth Radiation Budget Satellite (ERBS) during the period 19922004 have been analyzed using a multifunctional regression model. In general, responses of solar signal on temperature and ozone profiles show good agreement for HALOE and SAGE II measurements. The inferred annual-mean solar effect on temperature is found to be positive in the lower stratosphere (max $1.2 \pm 0.5 \mathrm{~K} / 100 \mathrm{sfu}$ ) and near stratopause, while negative in the middle stratosphere. The inferred solar effect on ozone is found to be significant in most of the stratosphere $(2 \pm 1.1-4 \pm 1.6 \% / 100 \mathrm{sfu})$. These observed results are in reasonable agreement with model simulations. Solar signals in ozone and temperature are in phase in the lower stratosphere and they are out of phase in the upper stratosphere. These inferred solar effects on ozone and temperature are found to vary dramatically during some months, at least in some altitude regions. Solar effects on temperature are found to be negative from August to March between $9 \mathrm{mb}-3 \mathrm{mb}$ pressure levels while solar effects on ozone are maximum during January-March near $10 \mathrm{mb}$ in the Northern Hemisphere and $5 \mathrm{mb}-7 \mathrm{mb}$ in the Southern Hemisphere.
\end{abstract}

Keywords. Ionosphere (Solar radiation and cosmic ray effects) - Atmospheric composition and structure (Pressure, density and temperature) - Meteorology and atmospheric dynamics (Middle atmosphere dynamics)

Correspondence to: S. Fadnavis

(suvarna@tropmet.res.in)

\section{Introduction}

It has been proposed that variations in Ultra Violet (UV) irradiance associated with the 11-year solar cycle affect the thermal and chemical structures of the middle atmosphere. Changes in UV irradiance can influence these structures in the middle atmosphere through modification of photochemical dissociation rates with associated effects on ozone (Hood, 1986; Huang and Brasseur, 1993; Fleming et al., 1995). Solar radiations between $200 \mathrm{~nm}$ and $240 \mathrm{~nm}$ are primarily responsible for formation of ozone in the stratosphere. Changes in irradiance influence directly the heating rates of equatorial upper stratosphere. Subsequent changes in stratospheric temperature and wind resulting from this perturbation in radiative heating could propagate downward, affecting the tropospheric circulation and climate (Haigh, 1996, 1999; Rind et al., 2002). An 11-year solar modulation of stratospheric ozone would have an impact on chemical and thereby thermal structures of the stratosphere and mesosphere (Brasseur et al., 1987; Wuebbles et al., 1991; Haigh, 1996). For this reason, solar-induced changes in stratospheric ozone are critical for determining the exact nature of the atmospheric response to solar variability.

A number of both modeling and observational studies have reported the effects of 11-year solar variability on ozone and temperature over the low-latitude regions (Callis and Nealy, 1987; Stolarski et al., 1991; Brasseur, 1993; Fleming et al., 1995; Haigh, 1996). To assess the potential impact of solar UV changes on stratospheric ozone, both the 2-D photochemical transport models (Brasseur, 1993; Haigh, 1994; Fleming et al., 1995) and the General Circulation Models (GCMs) (Shindell et al., 1999) have been used. These studies predict a maximum change of around $2-4 \%$ near $40 \mathrm{~km}$ with gradually decreasing changes above and below this height. There are model simulations focused on the solar response on total ozone whose main contribution comes from the lower stratosphere (Jackman et al., 1996; Zerefos et al., 1997). The

Published by Copernicus GmbH on behalf of the European Geosciences Union. 
observed changes in total ozone associated with 11-year solar variability are within 1-2\% according to analyses of groundbased (Angell, 1989; Miller et al., 1992; Zerefos et al., 1997) and global satellite ozone records (Chandra and McPeters, 1994; Hood, 1997; Randel et al., 1999). Predicted changes in ozone column amounts are $\sim 1.5 \%$ with small seasonal variation. The Solar Backscattered Ultra Violet (SBUV) ozone column data also show a solar signal of $\sim 1.5-2 \%$ in the global mean total ozone (Hood, 1997). Ozone profiles obtained from Nimbus 7 SBUV during the period 1980-1995 indicate an increase of $\sim 4 \%$ from solar minimum to solar maximum in the tropical upper stratosphere. In the upper stratosphere of low latitudes, changes associated with the solar variation increase with altitude and attain a maximum value near $43 \mathrm{~km}$ (McCormack and Hood, 1996; Chandra and McPeters, 1994). In the equatorial middle atmosphere SBUV ozone for the period 1979-1993 (McCormack and Hood, 1996; Lee and Smith, 2003) and SAGE II ozone for the period 1984-1998 (Lee and Smith, 2003) show the existence of a negative solar response near $30 \mathrm{~km}$. Lee and Smith (2003) reported that this may be associated with the Quasi-Biennial Oscillation (QBO) and two major volcanic eruptions: El Chichon in 1982 and Mount Pinatubo in 1991. In support of this suggestion, they ran a 2-D model simulation considering 11-year solar flux variations as only external forcing (without QBO or volcanic effects) and this showed positive peak values in the equatorial upper stratosphere. In contrast to the negative solar response in SBUV and SAGE II observations (Lee and Smith, 2003), 2-D and GCM model studies predict a strong positive response of $\sim 2-4 \%$ near the stratopause. Similarly, over lower stratosphere these models predicted that the solar response is much smaller than observational records. The Nimbus 7 SBUV ozone profile data show that changes in ozone associated with solar variability at the $40-50-\mathrm{km}$ altitude range are larger by a factor of 2 compared to these model predictions (Hood and Soukharev, 2001).

Similar to ozone, there are substantial differences between the observational and model predicted solar effects on temperature. Fourteen years (1980-1995) of National Meteorological Center (NMC) temperature data show a temperature increase of $1-2 \mathrm{~K}$ from solar minimum to solar maximum, from lower to upper stratosphere, passing through a negative value $\sim-1 \mathrm{~K}$ near $32 \mathrm{~km}$ (McCormack and Hood, 1996; Ramaswamy et al., 2001). In the lower stratosphere, the solar effect in a 2-D model is much smaller than the observed changes (Brasseur, 1993). In agreement with the NMC observations, SSU/MSU satellite measurements (Hood, 2004), Observatorie-Haute-Provence (OHP) lidar records (Keckhut et al., 1995), and rocket records (Kokin et al., 1990) recorded a negative solar effect near $30 \mathrm{~km}$. This alteration in sign with altitude is likely due to dynamical effects (Balachandran and Rind, 1995). On the other hand, Labitzke et al. (2002) and Labitzke (2001) reported a temperature increase of $1-2 \mathrm{~K}$ from solar minimum to solar maximum in the equatorial lower stratosphere with a strong signal near $25 \mathrm{~km}$. Keckhut et al. (2005) reported a 1-2 K positive effect in the middle and upper stratosphere. Dunkerton et al. (1998) found a $+1.1-\mathrm{K}$ response to the solar cycle integrated over the altitude range $29-55 \mathrm{~km}$. In agreement with the 2-D (Brasseur, 1993; Haigh, 1994) and GCM (Shindell et al., 1999) model predictions, the overlap-adjusted MSU-SSU data show a solar effect of $0.2-0.8 \mathrm{~K}$ over tropical stratosphere with a maximum (0.8 K) near $40 \mathrm{~km}$ (Ramaswamy et al., 2001; Hood and Soukharev, 2001).

Using HALOE temperature data, Remsberg and Deaver (2005) analyzed the solar cycle response over the latitude zones from $40^{\circ} \mathrm{N}$ to $40^{\circ} \mathrm{S}$, divided into $10 \mathrm{deg}$ wide latitudinal belts. Over the upper stratosphere they reported a solar signal with amplitudes varying from 0.72 to $1.18 \mathrm{~K}$. The correlation between the solar cycle and stratospheric temperature has been studied by Loon and Labitzke (1999) and Crooks and Gray (2005), who suggested a possible interaction between the solar cycle and the QBO signal. Very few studies have been reported on the inter relationship of decadal solar response in temperature and ozone (Saraf and Beig, 2003; Hood et al., 1993). Decadal solar variations of ozone and temperature were in phase in the upper stratosphere and they were out of phase in the lower stratosphere (Saraf and Beig, 2003). Saraf and Beig (2003) have investigated these interconnections for the lower stratosphere. However, their study was limited to a specific region.

As evident from the above discussions, although a number of scattered modeling and limited observational results are available, they differ considerably. Simultaneous intercomparison of solar signal in ozone and temperature has not been adequately archieved so far. Moreover, seasonal variation in the solar signal of temperature and ozone using satellite data has not yet been attempted. Here in order to narrow down the uncertainty and to address the above-mentioned problem, an attempt has been made to study the solar effect on ozone and temperature for all stratospheric altitudes over the tropical belt, as revealed from a variety of simultaneous measurements made by the HALOE and SAGE II instruments from 1992 to 2004. Results obtained are compared with earlier available results and discussed in detail.

\section{Data and analysis}

The vertical structure of middle atmospheric temperature as well as the concentrations of ozone and other species has been monitored by HALOE from October 1991 to the present. The operation of the HALOE instrument has been terminated by the end of 2005. Since HALOE is a solar occultation instrument, measurements are only made during limb-viewing conditions (sunrise and sunset). The latitudinal coverage of these measurements is from $80^{\circ} \mathrm{S}$ to $80^{\circ} \mathrm{N}$ over the course of a year. The UARS orbit has an inclination of $57^{\circ}$ and a period of about $96 \mathrm{~min}$. This results in 
the measurement of thirty profiles per day at two quasi-fixed latitudes (one corresponding to sunrise and the other corresponding to sunset). Data on temperature and ozone volume mixing ratio are stored as NETCDF files on the NASA website: http://haloethree.larc.nasa.gov/download/.

The present work analyzes monthly mean temperature and ozone profiles over the tropics $\left(30^{\circ} \mathrm{S}-30^{\circ} \mathrm{N}\right)$ for the period January 1992 to August 2004 and for the pressure levels from $54 \mathrm{mbar}$ to $0.8 \mathrm{mbar}$ - i.e. an approximate altitude range of 20 to $50 \mathrm{~km}$. Analysis has been performed over latitudinal belts of $0-30^{\circ} \mathrm{N}$ and $0-30^{\circ} \mathrm{S}$ separately. In a selected latitudinal belt 5-15 data points are available for a month. On average, there are about 6 sunrise/sunset measurements in a month during the years 1992 to 1998 . However, since 1999 the sampling of data for some months (like January) is poor. Hence, results of January should be concluded with precaution. However, for other months, sampling is much better.

HALOE does not retrieve temperature at altitudes above $5 \mathrm{mb}$, but rather uses the temperature estimates from the National Centre for Environmental Prediction (NCEP) analysis. There is good agreement between the HALOE and NCEP temperatures in their altitude region of overlap $(35 \mathrm{~km}-$ $40 \mathrm{~km}$ ) (Remsberg et al., 2002). Sunrise and sunset data are separately analyzed to avoid interference due to diurnal cycle. However, measurements are made at different periods of the month (for example, in January 1992, profiles are obtained at the end of the month while in January 1993 profiles are obtained at the beginning of the month). This may also lead to minor tidal interferences. Sunrise and sunset solar effects are averaged over a $0-30^{\circ} \mathrm{N}$ belt. Similarly, they are averaged over a $0-30^{\circ} \mathrm{S}$ belt.

Along with HALOE measurements, the SAGE II measurements (version 6.2) for ozone and temperature are obtained over the same period and region. The SAGE II sensor was launched in October 1984. This instrument uses the solar occultation technique to measure attenuated solar radiation through the Earth's limb. Hence, it vertically scans the limb of the atmosphere during spacecraft sunsets and sunrises. The $57^{\circ}$ inclined orbit of the ERBS spacecraft evenly distributes the SAGE II measurements every $24^{\circ}$ of longitude along a slowly shifting latitude circle. Ozone measurements are carried out in a channel centered at $600 \mathrm{~nm}$ (Cunnold et al., 1989). Over the course of roughly 1 month, SAGE II recorded observations at latitudes between $80^{\circ} \mathrm{S}$ and $80^{\circ} \mathrm{N}$. Thus, about 15 profiles for each event, at sunrise and sunset but on a different day are available each month at a given latitude. The data used in the present study are available on the website: http://badc.nerc.ac.uk/data/sage2.

Sunrise and sunset data are analyzed separately to avoid diurnal cycle interference. Sunrise and sunset solar effects are then averaged over the tropical belts of $0-30^{\circ} \mathrm{N}$. Similarly, they are averaged over the belt of $0-30^{\circ} \mathrm{S}$. Zonally averaged, monthly-mean data are thus used for each pressure level in our analysis.
In order to remove the effects of signals other than the 11year solar cycle - that is, natural periodic signals like the QBO and ENSO, as well as the linear trend in solar irradiance - we use a regression model, which is an extended version of the model of Stolarski et al. (1991) and Randel and Cobb (1994). The general expression for the regression model equation can be written as follows:

$$
\begin{gathered}
\theta(t, z)=\alpha(z)+\beta(z) \operatorname{Trend}(t)+\gamma(z) Q B O(t)+ \\
\delta(z) \operatorname{Solar}(t)+\varepsilon(z) \operatorname{ENSO}(t)+\operatorname{resid}(t),
\end{gathered}
$$

where $\theta(\mathrm{t}, \mathrm{z})$ are monthly mean temperature or ozone volume mixing ratios. The model uses the harmonic expansion to calculate coefficients $\alpha, \beta, \gamma$, and $\delta$. The harmonic expansion for $\alpha(\mathrm{t})$ is given as:

$$
\begin{aligned}
& \alpha(t)=\mathrm{A} 0+\mathrm{A} 1 \cos \omega t+\mathrm{A} 2 \sin \omega t+\mathrm{A} 3 \cos 2 \omega t \\
& \quad+\mathrm{A} 4 \sin 2 \omega t+\mathrm{A} 5 \cos 3 \omega t+\mathrm{A} 6 \sin 3 \omega t+\mathrm{A} 7 \cos 4 \omega t \\
& \quad+\mathrm{A} 8 \sin 4 \omega t,
\end{aligned}
$$

where $\omega=2 \pi / 12 ; \mathrm{A} 0, \mathrm{~A} 1, \mathrm{~A} 2 \ldots \ldots$ are constants and $t$ $(t=1,2 \ldots . \mathrm{n})$ is the time index. $\alpha, \beta, \gamma, \delta$ and $\varepsilon$ are calculated at every altitude and hence they are altitude (pressure level) (z) dependent in Eq. (1). For a particular altitude (pressure level) these are calculated for every month and hence are time dependant in Eq. (2).

As a QBO proxy, QBO (t), we use Singapore monthlymean QBO zonal winds $(\mathrm{m} / \mathrm{s})$ at 30 mbar. For the solar flux time series solar (t), we use the Ottawa monthly-mean F10.7 solar radio flux (standard flux units (sfu)). As an ENSO proxy ENSO $(t)$ we use the Southern Oscillation Index (SOI), which is the Tahiti $\left(18^{\circ} \mathrm{S}, 150^{\circ} \mathrm{W}\right)$ minus Darwin $\left(13^{\circ} \mathrm{S}, 131^{\circ} \mathrm{E}\right)$ monthly-mean sea-level pressures (mbar). Here, $\alpha(\mathrm{z}) \beta(\mathrm{z}) \gamma(\mathrm{z}), \mathrm{g} \delta(\mathrm{z})$ and $\varepsilon(\mathrm{z})$ are the time-dependent, 12-month, seasonal, trend, QBO, solar flux and ENSO coefficients, respectively, and resid ( $\mathrm{t}$ ) represents the residues or noise. The model performs multiple regression analyses of time series at each given pressure level. In the present study, the solar effect on stratospheric sunrise temperature and sunset temperature are obtained separately at each given stratospheric pressure level, using the above-mentioned multifunctional regression model. Sunrise and sunset solar coefficients are then averaged to obtain a single solar coefficient at each level. Similar analysis is done for the ozone time series. Solar coefficients obtained are significant at the one sigma error level $(68.3 \%$ confidence level). The time series of zonal mean, latitudinally averaged $\left(0-30^{\circ} \mathrm{N}\right.$ and $\left.0-30^{\circ} \mathrm{S}\right)$ HALOE sunrise and sunset temperatures over the period January 1992-August 2004 at 10 mbar $(\sim 32 \mathrm{~km})$ are shown in Fig. 1. It indicates adequate sampling over the selected latitudinal belts.

Both HALOE and SAGE II instruments are solar occultation instruments, where measurements are made only during limb-viewing conditions (sunrise and sunset). Their latitudinal coverage is from $80^{\circ} \mathrm{S}$ to $80^{\circ} \mathrm{N}$ over the course of a year. About 15 profiles for each event, at sunrise and sunset 

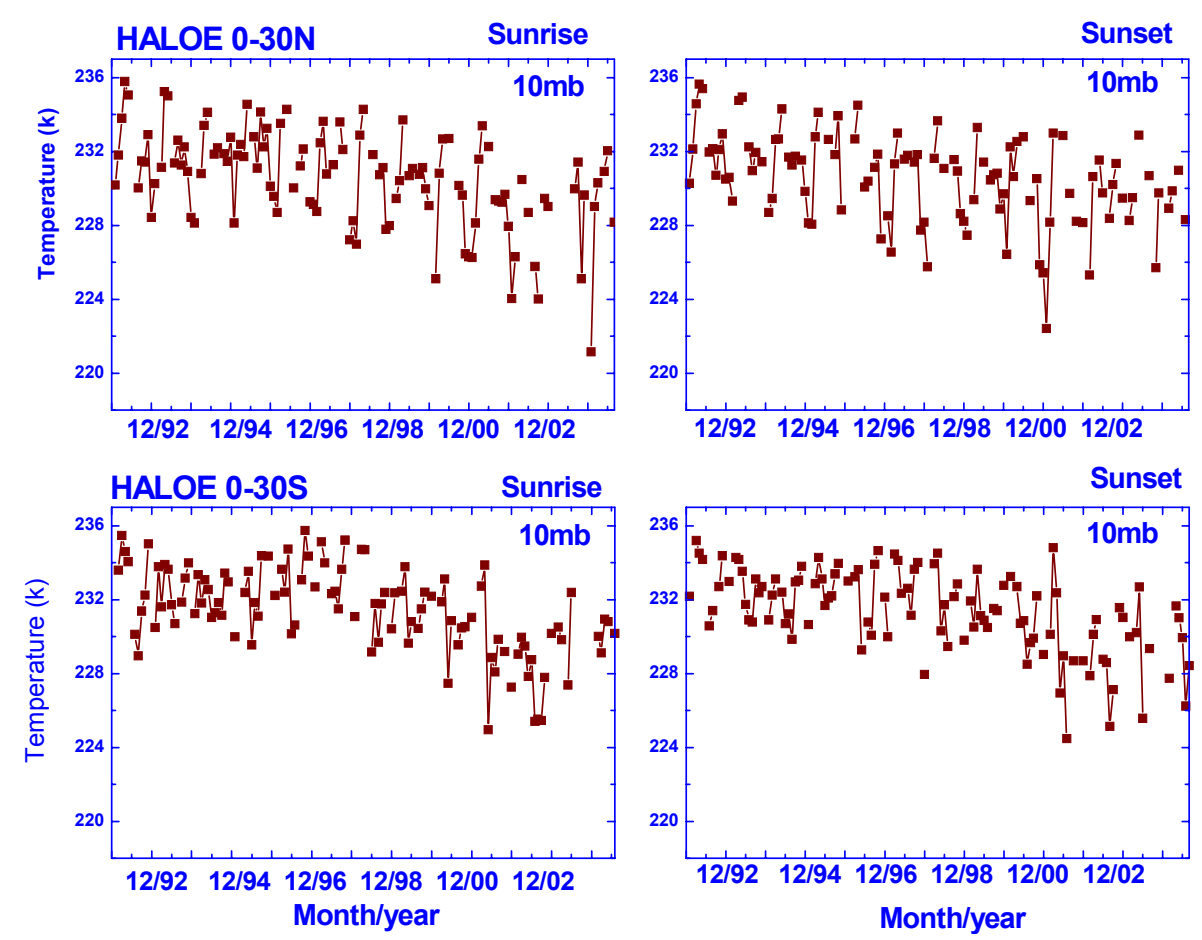

Fig. 1. Time series of zonal mean $\left(0-30^{\circ} \mathrm{N}\right)$ and $\left(0-30^{\circ} \mathrm{S}\right)$ sunrise and sunset HALOE temperature over the period January $1992-$ August 2004 at $10 \mathrm{mb}(\sim 32 \mathrm{~km})$.

but on a different day, are available each month at a given latitude. Although there are similarities in the observations made by HALOE and SAGE II instruments, analyzed results may differ because of many reasons. Their spatial coverage may differ over the selected latitudinal belt (for example, for a month, HALOE may view $10-25^{\circ} \mathrm{S}$ and SAGE may view $12-30^{\circ} \mathrm{S}$ ). Their sampling period may differ (for example, during December 2002, SAGE II does not sample any data over $0-30^{\circ} \mathrm{S}$, where as HALOE samples 8 points during the same month and over same belt). Moreover, each instrument makes measurements at different periods in a month, which may give rise to tidal error.

Because of the limited duration of the data records (13 years), there is the possibility of aliasing between solar cycle variability and the nonlinear trend. Regression analysis used may not distinguish between a true signal in response to the 11-year solar cycle and the signal in response to the other geophysical forcing on quasi-decadal time scales. Longer observational data records, at least 2-3 decades, are necessary to isolate the solar cycle precisely.

In the discussion that follows, we group pressure levels $27 \mathrm{mb}-10 \mathrm{mb}(\sim 25 \mathrm{~km}-32 \mathrm{~km})$ as the middle stratosphere and $10 \mathrm{mb}-0.8 \mathrm{mb}(\sim 32 \mathrm{~km}-50 \mathrm{~km})$ as the upper stratosphere and the seasons as: Winter: December-January-February; Spring: March-April-May; Summer: June-July-August; Autumn: September-October-November.

\section{Results}

\subsection{Solar effect on ozone}

To estimate the seasonal distribution, solar regression coefficients for each month are averaged for all the years. These averaged monthly coefficients are further averaged to obtain an annual regression coefficient at that level. The vertical variation of the annually-averaged solar effect on HALOE and SAGE II ozone over $0-30^{\circ} \mathrm{N}$ and $0-30^{\circ} \mathrm{S}$ belts are shown in Figs. 2a and b, respectively, along with the one sigma error limit. These results are compared with the solar component obtained from the SBUV data (McCormack and Hood, 1996), 2-D model simulations (Brasseur, 1993; Haigh, 1994), 1-D model simulation (Fleming et al., 1995) and a GCM (Shindell et al., 1999). According to our analysis, the solar effect on HALOE and SAGE II ozone is negative near $23 \mathrm{mb}(\sim 26 \mathrm{~km})$ and then positive over the rest of the stratosphere, in both hemispheres and is statistically significant for almost all the heights. The magnitude of the solar coefficient varies with altitude. Over the $0-30^{\circ} \mathrm{N}$ latitudinal belt (Fig. 2a), solar effects on HALOE ozone are negligible at $27 \mathrm{mb}(\sim 25 \mathrm{~km})$, increasing to a maximum of $4 \pm 1.6 \% / 100 \mathrm{sfu}$ by around $10 \mathrm{mb}(\sim 32 \mathrm{~km})$, and declining above that level. It remains almost constant at $2 \pm 1.1 \% / 100$ sfu in the middle stratosphere and then becomes insignificant near the stratopause. Solar effects on SAGE II ozone exhibit similar variations as those seen in the HALOE 


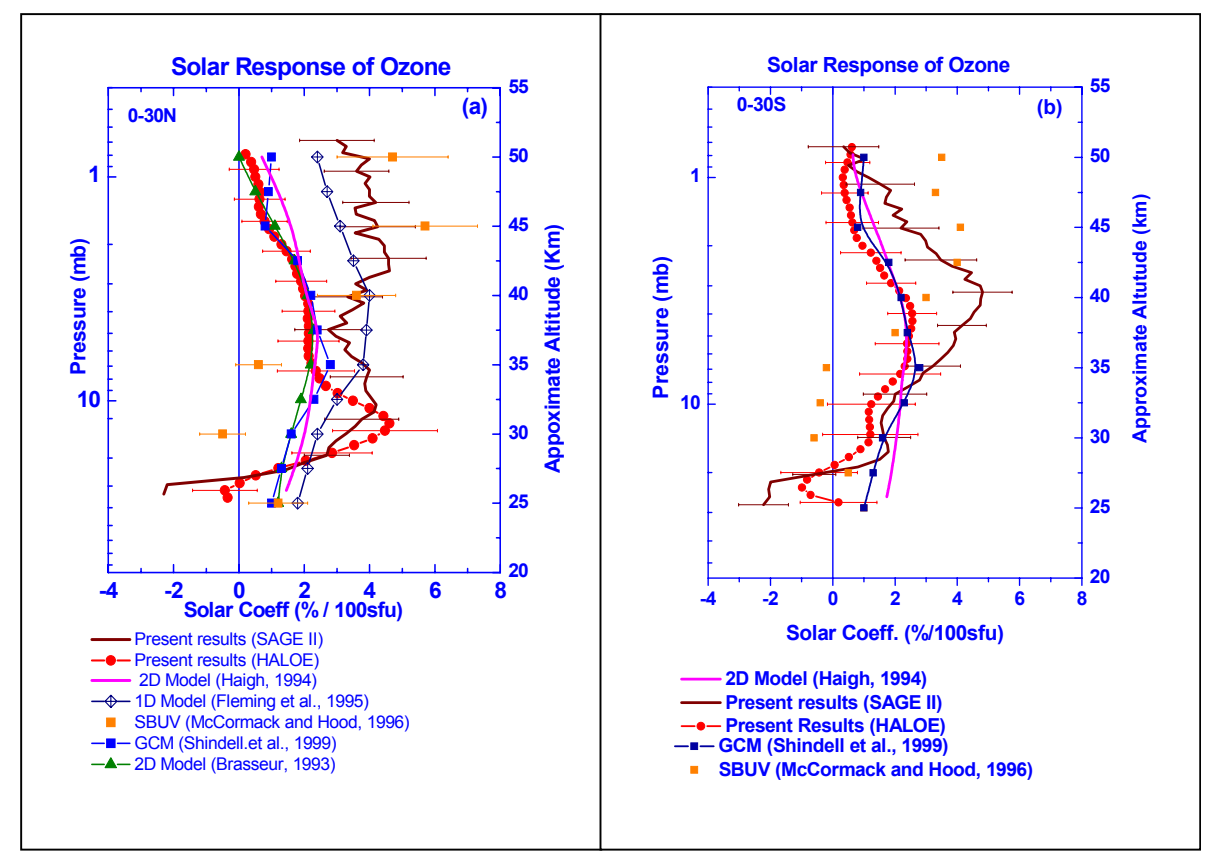

Fig. 2. The vertical distribution of annual mean solar coefficient of ozone (\%/100 sfu) as obtained in the present study (- HALOE profile) and (- SAGE II profile) are compared with the results from SBUV data (McCormack and Hood, 1996), indicated by the scatter plot (-), 2-D model (Haigh, 1994) ( -X-), 1-D model (Fleming et al., 1995) (-+), GCM (Shindell et al.,1999) (--), 2-D model (Brasseur, 1993) ( -) over (a) $0-30^{\circ} \mathrm{N}(\mathrm{b}) 0-30^{\circ} \mathrm{S}$ latitudinal belts.

profile in the middle stratosphere, except for an additional peak near $2 \mathrm{mb}-3 \mathrm{mb}$. The reason for this peak could be that both HALOE and SAGE II observations are made at a different period in a month and the sampling period of these instruments also differs. This can give rise to tidal error, which amplifies with an increase in altitude. Spatial coverage of these instruments can differ for a month over a selected latitudinal belt.

In general, HALOE, SAGE II, 2-D, 1-D models and GCM profiles show similar variations and positive solar responses over $22 \mathrm{mb}-0.7 \mathrm{mb}(27 \mathrm{~km}-50 \mathrm{~km})$. In the upper stratosphere of the $0-30^{\circ} \mathrm{N}$ belt, 2-D model simulation (Brasseur, 1993; Haigh, 1994) and GCM (Shindell et al., 1999) profiles lie within one sigma error limit of the HALOE profile. In contrast to HALOE, SAGE II, 2-D, 1-D models and GCM results, SBUV (McCormack and Hood, 1996; Lee and Smith, 2003) and SAGE II (Lee and Smith, 2003) ozone data indicate a negative solar effect in the equatorial middle stratosphere. This apparent negative effect has been attributed to QBO and two major volcanic eruptions, separated by about 9 years. Both eruptions occurred after the solar maximum in the SBUV and SAGE II data periods. The volcanic effect on the solar cycle analysis of ozone variability, using multiple regressions, is expected to be significant. These major volcanic eruptions enhanced the amount of stratospheric aerosol loading in the equatorial lower stratosphere, which induced intensified upward motion and reduced the equatorial lower stratospheric ozone for 3-4 years after the eruption (Lee and Smith, 2003). In support of this suggestion, they ran a 2-D model simulation considering the 11-year solar flux variation as only external forcing (without QBO or volcanic effects) and this showed positive peak values in the equatorial upper stratosphere. Study of ozonesonde data from various stations in India shows a solar effect of $\sim 4-15 \% / 100$ sfu over the middle stratosphere, with a maximum near $32 \mathrm{~km}$ (Saraf and Beig, 2003). Although the amplitude of the solar effect is much higher than in the present study (which may be due to the specific locations of the ozonesonde observations), the peak near $32 \mathrm{~km}$ is consistent with our analysis.

Figure $2 b$ exhibits the vertical profile of the annual mean solar effect on ozone over the $0-30^{\circ} \mathrm{S}$ belt. Similar to the $0-30^{\circ} \mathrm{N}$ latitudinal belt, the solar effects in the HALOE and SAGE II ozone are negative near $23 \mathrm{mb}(26 \mathrm{~km})$ which then increase to a maximum of $4 \pm 0.95 \% / 100$ sfu near $3 \mathrm{mb}$ $(\sim 40 \mathrm{~km})$ in the SAGE II profile and $2 \pm 0.78 \% / 100$ sfu near $4 \mathrm{mb}(\sim 38 \mathrm{~km})$ in the HALOE profile, and declines above that level. In general, HALOE and SAGE II profiles show similar variations. Their variabilities are within the one sigma error limit of each other in the middle stratosphere and near stratopause, while a significant difference can be seen only in the upper stratosphere. The maximum differences in their magnitude are observed near $2-3 \mathrm{mb}$. Similar to the $0-$ $30^{\circ} \mathrm{N}$ belt, the 2-D model (Haigh, 1994) and GCM (Shindell et al., 1999) simulation profiles agree well with the HALOE 


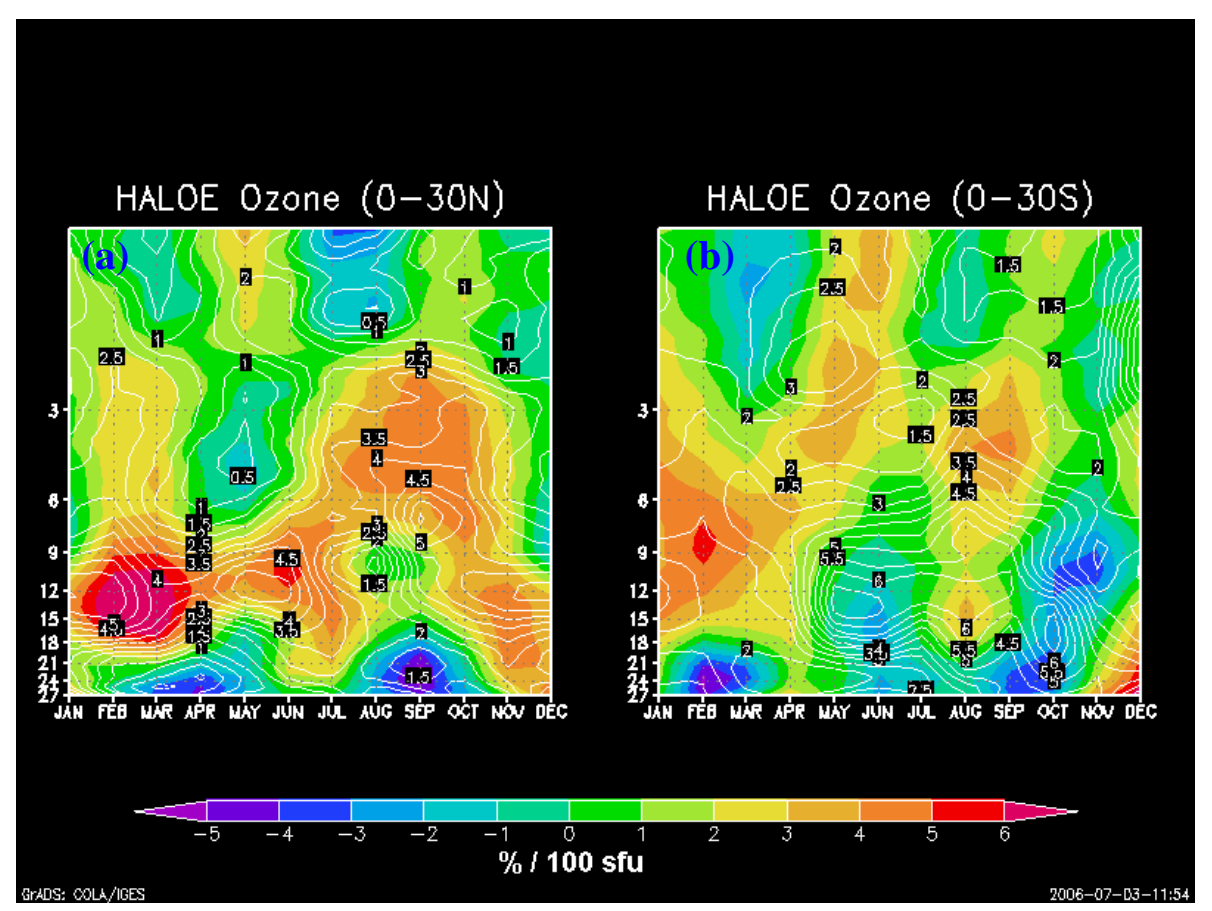

Fig. 3. Vertical distribution of the monthly variation of the solar coefficient (\%/100 sfu) obtained from the HALOE ozone (a) $0-30^{\circ} \mathrm{N}$ (b) $0-30^{\circ} \mathrm{S}$. Monthly variation of 1 sigma error $(\% / 100 \mathrm{sfu})$ in the solar effect on ozone is over-plotted with thin lines.

profile in the upper stratosphere. In general, the HALOE and SAGEII profiles are in good agreement with the 2-D model and GCM simulations but not with the SBUV results.

The HALOE and SAGE II profiles show similar variations in the respective belts. These profiles show good agreement in the middle stratosphere (they lie within the error bars of each other) while they differ in the upper stratosphere. Solar signals in the HALOE and SAGE II ozone show a peak in both the $0-30^{\circ} \mathrm{N}$ and $0-30^{\circ} \mathrm{S}$ belts at different altitudes. The HALOE profile exhibits a peak near $10 \mathrm{mb}(32 \mathrm{~km})$ in the Northern Hemisphere and rear $\sim 4 \mathrm{mb}(38 \mathrm{~km})$ in the Southern Hemisphere. Over the $0-30^{\circ} \mathrm{N}$ belt, the solar response in the SAGE II ozone shows two maxima, one near $10-\mathrm{mb}$ (similar to HALOE) and another near the $3-\mathrm{mb}$ level. In the Southern Hemisphere it shows only one peak near the 3 $\mathrm{mb}$ pressure level. Interestingly, the maximum solar effect on ozone (HALOE and SAGE II) near $10 \mathrm{mb}$ in the Northern Hemispheric belt and near $7 \mathrm{mb}-4 \mathrm{mb}$ in the Southern Hemispheric belt, as observed in the present analysis, have not been reported previously. This aspect is related to the seasonal distributions of the solar effect on ozone (see Discussion section).

Figures $3 \mathrm{a}$ and $\mathrm{b}$ show the monthly variation of the solar effect on ozone (\%/100 sfu), as obtained from HALOE, over $0-30^{\circ} \mathrm{N}$ and $0-30^{\circ} \mathrm{S}$, respectively, for the $27 \mathrm{mb}-0.8 \mathrm{mb}$ pressure levels $(\sim 25 \mathrm{~km}-50 \mathrm{~km})$. The corresponding one sigma error limit is over-plotted with thin lines. Over both the northern and southern belts, a positive solar coefficient of $\sim 2-6 \% / 100 \mathrm{sfu}$ is observed in most of the stratospheric region, with a pocket of negative coefficients during March and September near $27 \mathrm{mb}(\sim 25 \mathrm{~km})$. In the middle stratosphere, not much seasonal variation is seen, consistent with the results of Brasseur (1993) over the tropics. In the $18 \mathrm{mb}-$ $9 \mathrm{mb}(\sim 28 \mathrm{~km}-33 \mathrm{~km})$ region, a strong, positive solar coefficient with values greater than $6 \% / 100$ sfu are observed during the months of January, February and March, in the Northern Hemisphere. Similar high values are observed during these months but at higher altitudes $(\sim 8 \mathrm{mb})$ in the Southern Hemisphere. The effect of these high positive values can be seen as a peak in the annual mean profile. Oscillation of a $3-5$ month periodicity is observed above $2 \mathrm{mb}$ in both hemispheres.

Figures $4 \mathrm{a}$ and $\mathrm{b}$ show monthly distributions of the solar effect on SAGE II ozone over $0-30^{\circ} \mathrm{N}$ and $0-30^{\circ} \mathrm{S}$ belts, respectively. The corresponding one sigma error limit is overplotted with thin lines. A strong positive solar coefficient with values greater than $6 \% / 100 \mathrm{sfu}$ is observed near $10 \mathrm{mb}$ during January, February and March over the $0-30^{\circ} \mathrm{N}$ belt, which is observed at higher altitudes $(\sim 4 \mathrm{mb})$ in the Southern Hemisphere. Such a strong, positive solar coefficient is also observed in the solar effects on the HALOE ozone over similar pressure levels of respective latitudinal belts. The monthly distribution of solar effects on SAGE II ozone is quite similar to that of the HALOE ozone over the $0-30^{\circ} \mathrm{S}$ belt while their structure differs over the $0-30^{\circ} \mathrm{N}$ belt. Oscillation of a 3-5 month periodicity is observed above $2 \mathrm{mb}$ in both hemispheres. 


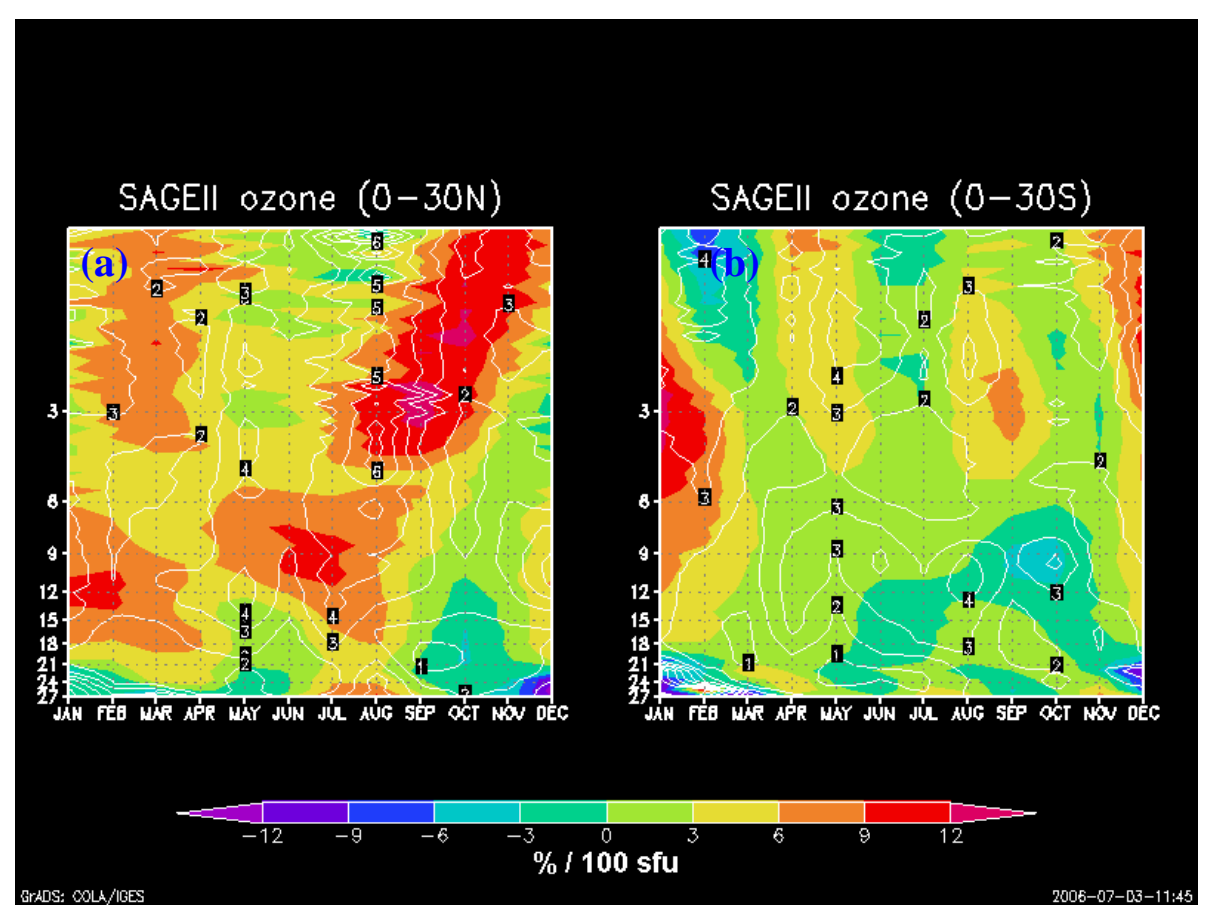

Fig. 4. Vertical distribution of monthly variation of solar coefficient (\%/100 sfu) obtained from SAGE II ozone (a) $0-30^{\circ} \mathrm{N}$ (b) $0-30^{\circ} \mathrm{S}$. Monthly variation of 1 sigma error $(\% / 100 \mathrm{sfu})$ in the solar effect on ozone is over-plotted with thin lines.

\subsection{Solar effect on temperature}

The vertical variations of the annual mean solar regression coefficient, $\delta(\mathrm{z})$, deduced from HALOE and SAGE II temperatures over the $0-30^{\circ} \mathrm{N}$ and $0-30^{\circ} \mathrm{S}$ belts, are shown in Figs. 5a and b, respectively, with a one sigma error limit. Figure 5 also shows the results obtained by Rocketsonde and SSU/MSU temperature (Keckhut et al., 2005), National Meteorological Center (NMC) temperature (McCormack and Hood, 1996), SBUV (McCormack and Hood, 1996), 2D model simulations (Brasseur, 1993 and Haigh, 1994), and one-dimensional Fixed Dynamical Heating (FDH) radiative model simulations (McCormack and Hood, 1996). Figure 5a shows that the solar coefficient obtained from the HALOE temperature is found to be significant in the lower (below $18 \mathrm{mb}$ that is below $28 \mathrm{~km}$ ) and upper stratosphere (above $2 \mathrm{mb}$ that is above $\sim 43 \mathrm{~km}$ ), but it is insignificant in the mid-stratosphere over the $0-30^{\circ} \mathrm{N}$ belt. Over the $0-30^{\circ} \mathrm{S}$ belt the HALOE profile shows similar variations but it is significant almost throughout the stratosphere. Over both belts the solar response in HALOE temperature is found to be highest $(\sim 1.1 \pm 0.23 \mathrm{~K} / 100 \mathrm{sfu})$ at about $27 \mathrm{mb}$ $(\sim 25 \mathrm{~km})$. This starts decreasing and becomes negligible between $7 \mathrm{mb}-2 \mathrm{mb}(35 \mathrm{~km}-43 \mathrm{~km})$. Above $2 \mathrm{mb}$ (above $43 \mathrm{~km}$ ), it again increases with height and reaches a value of $\sim 0.7 \pm 0.3 \mathrm{~K} / 100 \mathrm{sfu}$ near the stratopause. The minimum solar response in the HALOE temperature is more prominent in the Southern Hemisphere as compared to that in the North- ern Hemisphere. The vertical profile of the solar coefficients obtained from the SAGE II temperature shows similar variations as that of the HALOE profile over the respective belts, except for a minimum solar response near $5 \mathrm{mb}(37 \mathrm{~km})$ instead of $10 \mathrm{mb}(32 \mathrm{~km})$. In both $0-30^{\circ} \mathrm{N}$ and $0-30^{\circ} \mathrm{S}$ belts the HALOE and SAGE II profiles lie within the one sigma error limit of each other, except in the region of minimum solar response. The variation of the HALOE and SAGE II vertical profiles, as obtained in present study, are broadly consistent with the NMC (in the Northern Hemisphere) and the SBUV (in both hemispheres ) observational results in the middle stratosphere. The derived solar effects in the HALOE and SAGE II temperatures are smaller than the 2-D, FDH and SBUV results in the upper stratosphere and the SSU/MSU results (Keckhut et al., 2005) in the middle stratosphere over both hemispheres. The differences in the magnitudes of solar coefficients obtained by different workers could be due to the difference in the latitudinal region considered in each study. The 2-D results by Brasseur (1993) are at $5^{\circ} \mathrm{N}$, the 2 -D results by Haigh (1994) are over $0-30^{\circ} \mathrm{S}$, the SSU/MSU results are over the sub-tropics and the NMC results are over the entire globe. What is worth noting is that the shape of the vertical profiles is largely consistent with the results obtained here. Present results indicate (over both hemispheres) a minimum solar coefficient around $10 \mathrm{mb},(\sim 32 \mathrm{~km})$ in the HALOE profile and $5 \mathrm{mb}(\sim 37 \mathrm{~km})$ in the SAGE II temperature profile, where the coefficient becomes negative. It is insignificant in the HALOE and SAGE II profiles over the 


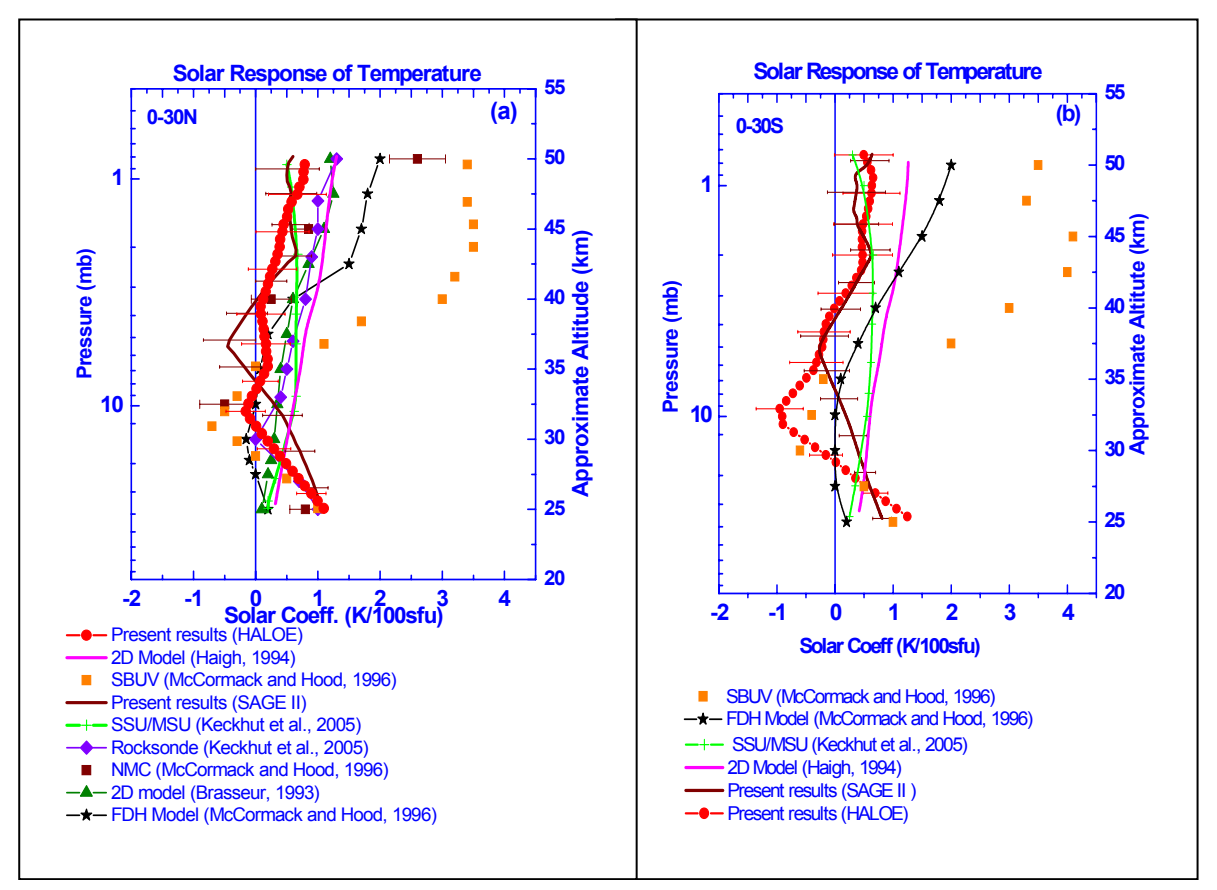

Fig. 5. The vertical distribution of the annual mean solar coefficient of temperature (K/100 sfu) as obtained in the present study (- HALOE profile) and (- SAGE II profile) are compared with Rocketsonde (Keckhut et al., 2005) (-§-), SSU/MSU (Keckhut et al., 2005) (-+-), NMC results (McCormack and Hood, 1996) (-), FDH model results (McCormack and Hood, 1996) (-*-), 2-D model results (Brasseur, 1993) (-) and 2-D model results (Haigh, 1994) (- ) over (a) $0-30^{\circ} \mathrm{N}$ (b) $0-30^{\circ} \mathrm{S}$ latitudinal belts.

$0-30^{\circ} \mathrm{N}$ belt. It is significant in the SAGE II profile and insignificant in the HALOE profile over the $0-30^{\circ} \mathrm{S}$ belt. The change in temperature from NCEP to the $\mathrm{HALOE} \mathrm{CO}_{2}$ channel, near $5 \mathrm{mb}(\sim 37 \mathrm{~km})$, may affect these altitudes. This may be the reason why the HALOE profile shows solar minimum at a different pressure level than that of the SAGE II profile. A negative solar response is also evident in the SBUV, NMC and FDH model profiles, as shown in Fig. 5. Such negative solar response is also observed over northern latitudes in satellite derived profiles (Ramaswamy et al., 2001), in the OHP lidar record (Keckhut et al., 1995) and in a rocket record (Kokin et al., 1990) near $30 \mathrm{~km}$. Balachandran and Rind (1995) reported that this alternation of the sign of the solar signal could be due to a dynamical effect. Consistent with the present results, Hood (2004) found a positive temperature response maximizing at the stratopause. Later, it decreases to $0 \mathrm{~K}$ and $-1 \mathrm{~K}$ at $34 \mathrm{~km}$ and $32 \mathrm{~km}$, respectively.

Model simulations by Huang and Brasseur (1993) found less than a $1.5-\mathrm{K}$ increase in temperature due to an increase in solar activity associated with the 11-year solar cycle. At mid stratospheric levels, $13 \mathrm{mb}-3 \mathrm{mb}(30 \mathrm{~km}-40 \mathrm{~km})$, the observed variability (in HALOE SAGE II SBUV and NMC) is less than the model predictions. From the HALOE temperature, the solar coefficient derived by Remsberg and Deaver (2005) varies from $0.72 \mathrm{~K}$ to $1.18 \mathrm{~K}$ over tropics $\left(10^{\circ}\right.$ wide belts) in the upper stratosphere $(35 \mathrm{~km}-50 \mathrm{~km})$. Solar coefficients obtained in the present study are smaller than those reported in Remsberg and Deaver (2005). This could be due to an averaging of responses in the temperature profiles over the entire tropical belt. From the ERA-40 data set for the period 1979-2001, Crooks and Gray (2005) found a positive solar effect throughout the tropical stratosphere, with an amplitude of $1.75 \mathrm{~K}$, peaking at $43 \mathrm{~km}$. In the middle stratosphere solar coefficients were observed to vary from 0.18 to $0.81 \mathrm{~K} / 100$ sfu over different Indian stations (Saraf and Beig, 2003). Using radiosonde and rocketsonde data, Angell (1991) estimated a solar cycle variation of approximately $0.2 \mathrm{~K}-0.8 \mathrm{~K}$, from the lower to upper stratosphere. The overlap-adjusted SSU plus MSU data sets deduce a solar component of the order of $0.5 \mathrm{~K}$ to $1.0 \mathrm{~K}$ throughout the low-latitude stratosphere (Hood and Soukharev, 2001). Ramaswamy et al. (2001) reported a solar signal of $\sim 0.5 \mathrm{~K}-$ $1.0 \mathrm{~K}$ in the Nash (SSU 15X) satellite data. These results are broadly in agreement with ours.

Monthly variations in the vertical profile of the solar coefficient in the HALOE temperature over $0-30^{\circ} \mathrm{N}$ and $0-30^{\circ} \mathrm{S}$ are plotted in Figs. 6a and b, respectively; the corresponding one sigma error limit is over-plotted with thin lines. The most obvious feature is that both the $0-30^{\circ} \mathrm{N}$ and $0-30^{\circ} \mathrm{S}$ belts exhibit strong, negative solar response $(<-2 \mathrm{~K} / 100 \mathrm{sfu})$ during August-October between $15 \mathrm{mb}-3 \mathrm{mb}$, with a minimum amplitude near $10 \mathrm{mb}(\sim 32 \mathrm{~km})$. The solar response over the $0-30^{\circ} \mathrm{N}$ belt shows another minimum near $4 \mathrm{mb}(\sim 38 \mathrm{~km})$. A negative solar response, although insignificant, persists 


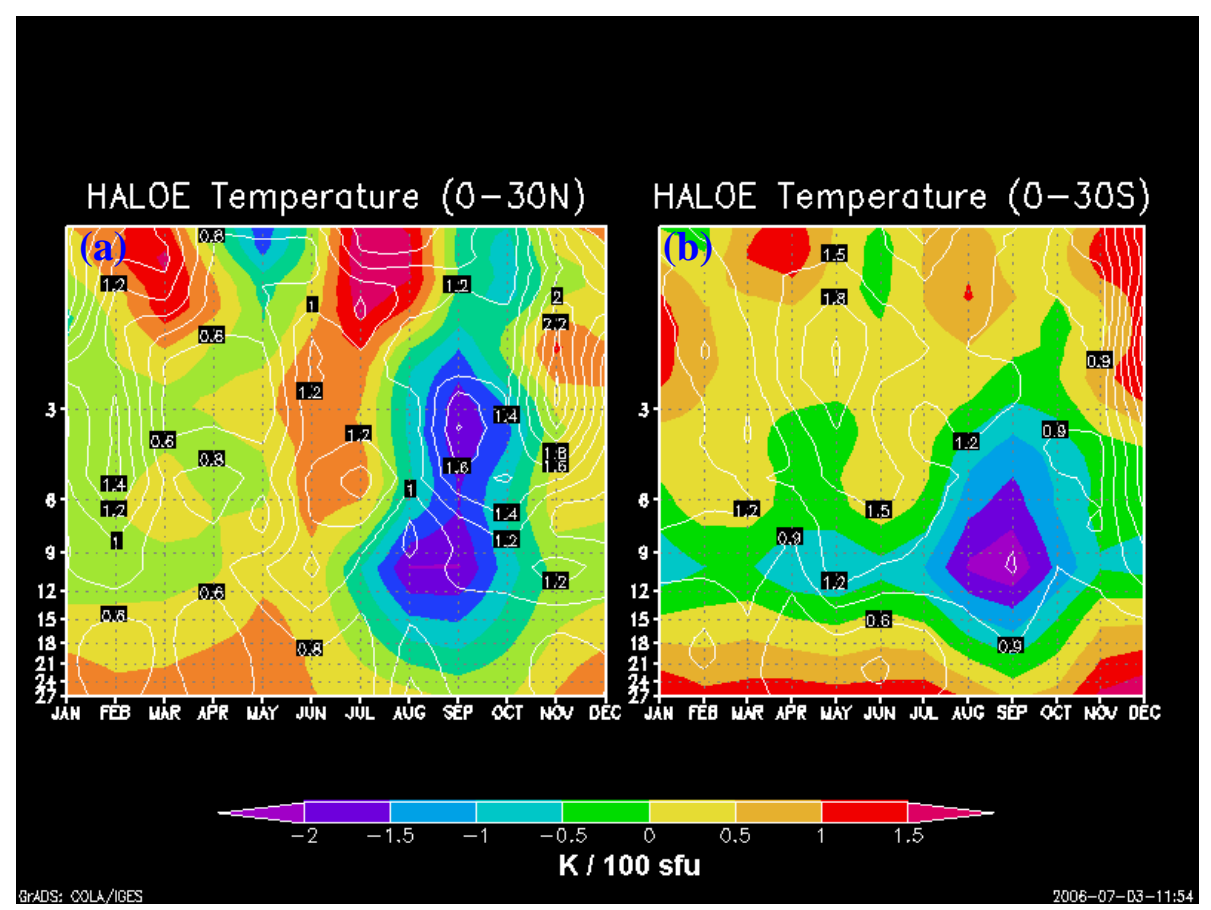

Fig. 6. Vertical distribution of the monthly variation of the solar coefficient (K/100 sfu) obtained from HALOE temperature (a) $0-30^{\circ} \mathrm{N}(\mathbf{b})$ $0-30^{\circ} \mathrm{S}$. Monthly variation of 1 sigma error in the solar effect on temperature is over-plotted with thin lines.

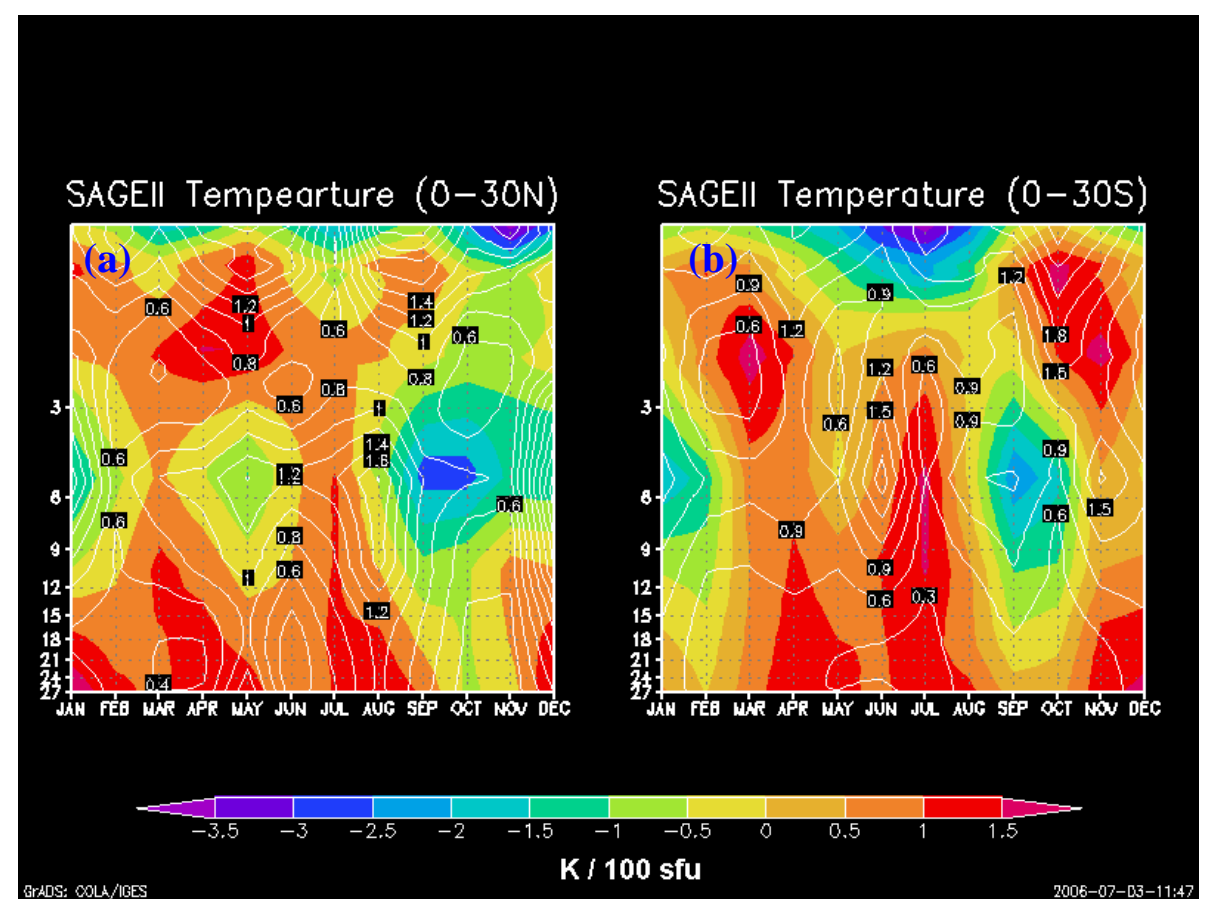

Fig. 7. Vertical distribution of monthly variation of solar coefficient (K/100 sfu) obtained from SAGE II temperature (a) $0-30^{\circ} \mathrm{N}(\mathbf{b}) 0-30^{\circ} \mathrm{S}$. Monthly variation of 1 sigma error $(\mathrm{K} / 100 \mathrm{sfu})$ in the solar effect on temperature is over-plotted with thin lines. 
until March in the Northern Hemisphere and throughout the year in the Southern Hemisphere. Cyclic variation with 35 month periodicity is evident above $2 \mathrm{mb}(\sim 43 \mathrm{~km})$ in the northern belt. This is also observed in the SAGE II temperature over the $0-30^{\circ} \mathrm{N}$ belt.

Figures $7 \mathrm{a}$ and $\mathrm{b}$ exhibit the monthly variation of solar coefficients for the SAGE II temperature over $0-30^{\circ} \mathrm{N}$ and $0-30^{\circ} \mathrm{S}$, with one sigma error limit over-plotted with thin lines. Similar to the HALOE temperature strong, negative coefficients $(<-2 \mathrm{~K} / 100 \mathrm{sfu})$ are also observed during August-October near $15 \mathrm{mb}-3 \mathrm{mb}$ with a minimum near $5 \mathrm{mb}$ $(\sim 37 \mathrm{~km})$ over northern and southern belts. These negative coefficients persist until February in both the hemispheres. In the Northern Hemisphere cyclic variation of 3-5 months, periodicity is observed near the stratopause. In general, positive responses are found for almost all months except for August-March at some pressure levels. These dips in temperature, are also reflected in the annual mean profile, which could be due to the dynamical effect.

If we compare monthly mean variations of solar response in temperature deduced from HALOE and SAGE II instruments over the Northern Hemisphere, the prominent common features are the dips in temperature near $4 \mathrm{mb}-5 \mathrm{mb}$ during August to October and the 3-5 months cyclic variations near the stratopause. Their structure over rest of the stratosphere differs. The probable reasons may be that observations are made at different periods in the month, or in the sampling periods these instruments also differ, or different latitudinal coverage occurs for a month within the belt. Similarly, over the $0-30^{\circ} \mathrm{S}$ belt common features of the solar signal in the HALOE and SAGE II temperature shows good agreement.

\section{Discussion}

Annual mean solar responses on HALOE and SAGE II ozone are in good agreement in the middle stratosphere. However, they differ in the upper stratosphere. The reasons for this disagreement could be that their observations are made at different periods in the month, and the sampling period of these instruments differs, which may give rise to tidal error. Tidal interference amplifies at higher altitude. Another reason could be their different latitudinal coverage in a month within the selected belt.

Annual mean solar response in the HALOE and SAGE II temperatures are in good agreement through out the stratosphere. In the upper stratosphere the solar response on HALOE and SAGE II ozone exhibits a disagreement, whereas their solar responses in temperature are in good agreement. The reason for the agreement in the upper stratosphere could be due to the inclusion of NCEP estimates above $5 \mathrm{mb}$ in the HALOE temperature profiles, which reduces the effect of tidal interferences.
Monthly mean variation of solar responses in ozone and temperature obtained from respective instruments show a similarity in prominent features over both hemispheres. Both HALOE and SAGE II ozone show an enhanced solar response near $10 \mathrm{mb}(\sim 32 \mathrm{~km})$ in the Northern Hemisphere, and $\sim-7 \mathrm{mb}-4 \mathrm{mb}$ in the Southern Hemisphere during January-March (winter and beginning of spring). In both hemispheres, HALOE and SAGE II temperatures show a negative solar response from August to February while keeping the strong amplitude during August-October (late summer and early autumn) at $10 \mathrm{mb}$ and at $5 \mathrm{mb}$, respectively. It is interesting to note that over both hemispheres, the solar response in temperature shows a dip $(10 \mathrm{mb}$ HALOE and $5 \mathrm{mb}$ in SAGE II) during August to October (autumn) while the solar response in ozone shows an enhancement during the following season (winter) at similar altitudes.

The cyclic variation of 3-5 months periodicity is quite prominent in the altitudes above $2 \mathrm{mb}$ in the HALOE and SAGE II ozone over both belts, while in the solar response to temperature 3-5 month periodic variations can be seen in the SAGE II and HALOE only in the Northern Hemisphere.

It is evident from Figs. 3 and 6 that the solar response of the HALOE ozone is out of phase with the HALOE temperature in the upper stratosphere. However, they are in phase in the middle stratosphere (between $27 \mathrm{mb}$ and $18 \mathrm{mb}$ ). A similar phase relationship is also observed in the SAGE II ozone and temperature (Figs. 4 and 7). Saraf and Beig (2003) also reported a significant in phase relation between the solar component of the temperature and ozone in the middle stratosphere over different Indian stations, which is reasonably in agreement with the present results. The correlation between the solar component of the ozone and the solar component of the temperature shows a positive correlation in the middle stratosphere and a negative correlation in the upper stratosphere. The reason may be that since the majority of the apparent solar cycle variation of ozone takes place in the lower stratosphere (Hood, 1997; Wang et al., 1996), ozone increases from solar minimum to solar maximum. This increase in ozone will lead to an increase in UV absorption and therefore in temperature. Temperature also increases from solar minimum to solar maximum. Hence, the solar component of the ozone is positively correlated to the solar response of the temperature in the lower and middle stratosphere. In the upper stratosphere the solar response of the ozone to the solar cycle takes place through a temperature dependence of reactions (1) $\mathrm{O}+\mathrm{O}_{3} \rightarrow 2 \mathrm{O}_{2}$, (2) $\mathrm{O}+\mathrm{O}_{2}+\mathrm{M} \rightarrow \mathrm{O}_{3}+\mathrm{M}$. The temperature increases from solar minimum to solar maximum. Ozone changes are anti-correlated to the temperature variations due to the inverse dependence of the above photochemical reaction rates of ozone on temperature (Saraf and Beig, 2003). Therefore, the solar component of the ozone and solar component of temperature are anti-correlated in the upper stratosphere, which is highest near the stratopause where temperature variation due to solar flux is also high. 
Our statistical analysis of the annual mean response of HALOE ozone (over $0-30^{\circ} \mathrm{N}$ and $0-30^{\circ} \mathrm{S}$ belts) to the 11year solar cycle matches reasonably with the 2-D model and the GCM profiles, as compared to SAGE II ozone profile. The agreement between the solar responses in the HALOE ozone to the model simulated results is particularly good over the upper stratosphere compared to the middle stratosphere. The solar response on the upper stratospheric SAGE II ozone agrees qualitatively with the HALOE and model simulated results. The reasons for this agreement, especially over the $3 \mathrm{mb}-0.8 \mathrm{mb}(\sim 40 \mathrm{~lm}-50 \mathrm{~km})$ pressure levels, could be that at these levels ozone is nearly in a state of photochemical equilibrium, where transport effects are less important, and ozone photochemistry is accurately simulated by these models. The annual solar effect on ozone obtained in the present study is stronger near $10 \mathrm{mb}(\sim 32 \mathrm{~km})$ and $\sim 3 \mathrm{mb}(\sim 40 \mathrm{~km})$ than that predicted by models. This discrepancy in this region could be due to less penetration of UV radiation in the Herzberg continuum $(200 \mathrm{~nm}-240 \mathrm{~nm})$ caused by greater absorption at higher altitudes. Therefore, ozone becomes less sensitive to photochemistry (Brasseur and Simon, 1990) and the distribution of ozone is controlled primarily by dynamics (McCormack and Hood, 1996). Dynamical phenomenon may be responsible for the observed peak.

The annually averaged solar effect on temperature obtained in the present study (SAGE II and HALOE, over $30^{\circ} \mathrm{N}$ and $0-30^{\circ} \mathrm{S}$ belts $)$ is stronger near $27 \mathrm{mb}(25 \mathrm{~km})$ and weaker in the upper stratosphere, as compared to model results. In contrast to model results, a weak (statistically insignificant), negative solar effect is observed near $10 \mathrm{mb}(\sim 32 \mathrm{~km})$ in HALOE and $5 \mathrm{mb}(\sim 37 \mathrm{~km})$ in SAGE II. Monthly distributions of solar effects on temperature reveal that this negative response takes place during August to March, between $18 \mathrm{mb}-3 \mathrm{mb}(28 \mathrm{~km}-40 \mathrm{~km})$, with a minimum during August-October near $10 \mathrm{mb}$ in HALOE and near $5 \mathrm{mb}$ $(\sim 37 \mathrm{~km})$ in SAGE II.

As noted above, our analysis finds that a feature in the annually averaged solar effect on ozone at $10 \mathrm{mb}\left(0-30^{\circ} \mathrm{N}\right)$ and $3 \mathrm{mb}\left(0-30^{\circ} \mathrm{S}\right)$ is much stronger than predicted in the models. On a monthly basis, a strong, positive response is observed during January-March. Over the same pressure levels, the annual mean solar effect on temperature becomes negative at $10 \mathrm{mb}$ in HALOE and $5 \mathrm{mb}(\sim 37 \mathrm{~km})$ in SAGE II temperature profiles. The change over of temperature from NCEP to the HALOE $\mathrm{CO}_{2}$ channel near $5 \mathrm{mb}$ may affect these pressure levels and this may be the reason for an observed negative minimum near $10 \mathrm{mb}$ instead of $5 \mathrm{mb}$. The monthly variation reveals that this strong, negative response takes place during August-March with a minimum amplitude during August-October, when the solar effect on temperature becomes negative with a strong amplitude during autumn and in the following season (winter) the solar effect on ozone shows an enhancement over the same pressure levels. This indicates that the dynamical phenomena may be affecting the solar signal at these altitudes. Because of the limited duration of data recorded (13 years), the regression analysis used may not isolate the true signal in response to the 11-year solar cycle from other nonlinear geophysical forcing, such a QBO. Longer observational data records, at least for 2-3 decades, are necessary to isolate the effect of the solar cycle precisely.

\section{Conclusions}

The HALOE and SAGE II temperature and ozone measurements are used for the investigation of the 11-year solar signal. Our analysis of this effect demonstrates a positive annual response in temperature and ozone over both belts $(0$ $30^{\circ} \mathrm{N}$ and $0-30^{\circ} \mathrm{S}$ ). The annually averaged signal in ozone (HALOE and SAGE II) is found to be of the order of around $1 \pm 0.5$ to $4 \pm 1.6 \% / 100$ sfu and highly significant in most of the stratospheric regions. The deduced solar response of the HALOE ozone is in a general agreement with the SAGE II ozone. Over the $0-30^{\circ} \mathrm{N}$ belt the solar signal in the HALOE ozone exhibits a pronounced peak near $10 \mathrm{mb}$ $(\sim 32 \mathrm{~km})$ and in the SAGE II ozone it shows an enhancement near $10 \mathrm{mb}(\sim 32 \mathrm{~km})$ and $3 \mathrm{mb}(\sim 40 \mathrm{~km})$. In the Southern Hemisphere solar signals in the HALOE and SAGE II ozone show an enhancement near $3 \mathrm{mb}$. The solar response in the HALOE ozone shows a very good agreement with the model simulated results in the upper stratosphere. A solar effect of $0.4 \pm 0.23$ to $0.8 \pm 0.46 \mathrm{~K} / 100 \mathrm{sfu}$ is observed in the lower and upper stratospheric temperature (HALOE and SAGE II), with a negative response in the middle stratosphere. Annual mean solar signals deduced from HALOE and SAGE II temperature are in good agreement throughout the stratosphere. Annual solar response in temperature shows a dip near $10 \mathrm{mb}(\sim 32 \mathrm{~km})$ in the HALOE profile and $5 \mathrm{mb}$ $(\sim 43 \mathrm{~km})$ in SAGE II profile. The solar effect on temperature indicates a negative response during August-March, with a minimum during autumn, while the solar effect on ozone indicates a high positive solar effect in the middle stratosphere during following season (winter). This dip in the temperature effect and peak in the ozone effect may be attributed to a dynamical phenomenon. More detailed investigation of this possibility is needed. The solar signal in ozone shows an in-phase relationship with temperature in the middle stratosphere. They are out of phase in the upper stratosphere.

Acknowledgements. The authors express gratitude to G. B. Pant (IITM) for his encouragement during the course of this study. Thanks are due to T. Anderson and R. Saylor for their valuable help in language editing. We are also grateful to two anonymous reviewers. We acknowledge the Climate and Weather of Sun Earth System-India (CAWSES) program of Indian Space Research Organization for the financial assistance to this project.

Topical Editor U.-P. Hoppe thanks two referees for their help in evaluating this paper. 


\section{References}

Angell, J. K.: Stratospheric temperature change as a function of height and sunspot number during 1972-1989 based on rocketsonde and radiosonde data, J. Climate, 4, 1170-1180, 1991.

Angell, J. K.: On the relation between atmospheric ozone and sunspot number J. Clim., 2, 1404-1416, 1989.

Balachandran, N. K. and Rind, D.: Modeling the effects of UV variability and the $\mathrm{QBO}$ on the troposphere system, I, The middle atmosphere, J. Clim., 8, 23 079-23 090, 1995.

Brasseur, G.: The response of the middle atmosphere to long term and short term solar variability: A two-dimensional model, J. Geophys. Res., 98, 23 079-23 090, 1993.

Brasseur, G. A., Rudder, De, Keating, G. M., and Pitts, M. C.: Response of middle atmosphere to short term solar ultraviolet variations, 2 Theory, J. Geophys. Res., 92, 903-914, 1987.

Brasseur, G. and Simon, P. C.: Stratospheric Chemical and thermal response of middle atmosphere to short-term solar ultraviolet variations, 2, Theory, J. Geophys, Res., 95, 5639-5655, 1990.

Callis, L. B. and Nealy, J. E.: Solar UV variability and its effect on stratospheric thermal structure and trace constituents, Geophys. Res. Lett., 5, 249-252, 1987.

Chandra, S. and McPeters, R. D.: The solar cycle variation of ozone in the stratosphere inferred from Nimbus 7 and NOAA 11 satellites, J. Geophys. Res., 99, 20 665-20 671, 1994.

Crooks, S. A. and Gray, L. J.: Characterization of the 11 year solar signal using a multiple regression analysis of the ERA-40 Dataset, J. of Clim., 18, 996-1015, 2005.

Cunnold, D. M., Chu, W. P., Barnes, R. A., McCormick, M. P., and Veiga, R. E.: Validation of SAGE II ozone measurements, J. Geophys. Res., 94, 8447-8460, 1989.

Dunkerton, T. J., Delisi, D. P., and Baldwin, M. P.: Middle atmosphere cooling trend in historical rocketsonde data, Geophys. Res. Lett., 25, 3371-3374, 1998.

Fleming, E., Chandra, S., Jackman, C. H., Considine, D. B., and Douglass, A. R.: The middle atmosphere response to short and long term solar UV variation: Analysis of observations and two dimensional model results. J. Atmos. Terr. Phys., 57, 333-365, 1995.

Haigh, J. D.: A GCM study of climate change in response to 11 year solar cycle, Q. J. R., Meteoro, Soc., 125, 871-892, 1999.

Haigh, J. D.: The impact of solar variability on climate, Science, 272, 981-984, 1996.

Haigh, J. D.: The role of stratospheric ozone in modulating the solar radiative forcing of climate, Nature, 370, 544-546, 1994.

Hood, L. L.: Effects of solar UV variability on the stratosphere, in: Solar variability and its effect on the Earth's atmosphere and climate system, AGU Monograph Series, edited by: Pap, J. and Fox, P., American Geophysical Union, Washington D.C., Vol. 141, 283-303, 2004

Hood, L. L. and Soukharev, B. E.: The solar component of longterm stratospheric variability: observations, model comparisons and possible mechanisms, Proceedings of the SPARC 2000 Meeting, Mar del Plata, Argentina, O.2/14.available on CDROM, 2001.

Hood, L. L.: The solar cycle variations of total ozone: Dynamical forcing in the lower stratosphere, J. Geophys. Res., 102, 13551370, 1997.

Hood, L. L. and Jirikowic, J., and McCormack, J. P.: Quasi-decadal variability of the stratosphere: Influence of long term solar ultra- violet variations, J. Atmos. Sci., 50, 3941-3958, 1993.

Hood L. L.: Coupled stratospheric ozone and temperature response to short term changes in solar ultraviolet flux: An analysis of Nimbus 7 SBUV and SAMS data, J. Geophys. Res., 91, 52645276, 1986.

Huang, T. Y. W. and Brasseur, G.: Effect of long-Term Solar Variability in a Two-Dimensional Interactive Model of the Middle Atmosphere, J. Geophys. Res., 98, 20 413-20 427, 1993.

Jackman, C. H., Fleming, E. L., Chandra, S., Considine, B. D., and Rosenfield, J. E.: Past, present and future modeled ozone trends with comparisons to observed trends, J, Geophys. Res., 101, 28 753-28 767, 1996.

Keckhut, P., Cagnazzo, C., Chanin, M. L., et al.: The 11-year solarcycle effects on the temperature in the upper-stratosphere and mesosphere: Part I-Assessment of Observations, J. Atmos. Sol. Terres. Phys., 67, 948-958, 2005.

Ketchut, P., Hauchecorne, A., and Chanin, M. L.: Midlatitude longterm variability of the middle atmosphere: Trends and cyclic and episodic changes, J. Geophys. Res., 100, 18 887-18 897, 1995.

Kokin, G., Lysenko, Y., and Rozenfeld, S.: Temperature changes in the stratosphere and mesosphere in 1964-1988 based on rocketsonde data, Izv. Atmos. Oceanic Phys., 26(6), 518-523, 1990.

Labitzke, K., Austin, J., Butchart, A., Knight, J., Takahashi, M., Nakamoto, M., Nagashima, T., Haigh, J., and Williams, V.: The global signal of the 11-year solar cycle in the stratosphere: Observations and models, J. Atmos. and Solar Terr. Phy., 64, 203 210, 2002.

Labitzke, K.: The Global signal of the 11 year sunspot cycle in the stratosphere: Differences between solar maxima and minima, Meteorologische Zeitschrift, 10, 83-90, 2001.

Lee, H. and Smith, A.: Simulation of the combined effects of solar cycle, QBO, and volcanic forcing on stratospheric ozone changes in recent decades, J. Geophys. Res., 108(D2), 4049, doi:10.1029/2001JD001503, 2003.

Loon, H. van and Labitzke, K.:The signal of the 11-yearsolar cycle in the global stratosphere, J. Atmos. and Solar Terr. Phy., 61, 53$61,1999$.

McCormack, J. P. and Hood, L. L.: Apparent solar cycle variations of upper stratospheric ozone and temperature: Latitudinal and seasonal dependences, J. Geophys. Res., 101, 20 933-20 944, 1996.

Miller, A. J., Nagatani, R. M., Tiao, G. C., Niu, X. F., Reinsel, G. C., Wuebbles, D., and Grant, K.: Comparison of observed ozone and temperature trends in the lower stratosphere, Geophys. Res. Lett., 19, 929-932, 1992.

Ramaswamy, V., Chanin, M. L., Angell, J., et al.: Stratospheric temperature trends: Observations and model simulations, Rev. Geophys., 39, 71-122, 2001.

Randel, W. J., Stolarski, R. S., Cunnold, D. M., Logan, J. A., Newchurch, M. J., and Zawodny, J. M.: Trends in the Vertical Distribution of Ozone, Science, 285, 1689-1692, 1999.

Randel, W. J. and Cobb, J. B.: Coherent variations of monthly mean total ozone and lower stratospheric temperature, J. Geophys. Res., 99, 5433-5477, 1994.

Remsberg, E. E. and Deaver, L. E.: Interannual Solar cycle, and trend terms in middle atmospheric temperature time series from HALOE. J. Geophys. Res., 110, D06106, doi:10.1029/2004JD004905, 2005.

Remsberg, E. E., Bhat, P. P., and Deaver, L. E.: Seasonal 
and long-term variations in middle atmosphere temperature from HALOE on UARS, J. Geophys. Res., 107, D19, 4411, doi:10.1029/2001JD001366, 2002.

Rind, D. P., Lonergan N. K., Balachandran, N., and Shindell, D.: $2 \mathrm{xCO}_{2}$ and solar variability influences on troposphere through wave mean flow interaction, J. Meteorol Soc., Jpn., 80, 863-976, 2002.

Saraf, N. and Beig, G.: Solar Response in the Vertical Structure of Ozone and Temperature in the Tropical Stratosphere, J. Atmos. Solar Terr. Phys., 65(11-13), 1235-1243, doi:10.1016/j.jastp.2003.08.006, 2003.

Shindell, D., Rind, D., Balachandran, N., Lean, J., and Lonergan, J.: Solar cycle variability, Ozone and climate, science, 284, 305308, 1999.
Stolarski, R. S., Bloomfield, P., McPeters, R. D., and Herman, J. R.: Total ozone trends deduced from Nimbus 7 TOMS data, Geophys. Res. Lett., 18, 1015-1018, 1991.

Wang, H. J., Cunnold, D. M., and Bao, X.: A critical analysis of stratospheric aerosol and gas experiment ozone trends. J. Geophys. Res., 101, 12 495-12 514, 1996.

Wuebbles, D. J., Kinnison, D. E., Grant, K. E., and Lean, J.: The effect of solar flux variations and trance gas emissions on recent trends in stratospheric ozone and temperatutre, J. Geomagn. Geoelect., 43, 709-718, 1991.

Zerefos, C. S., Tourpali, K., Bojkov, B. R., and Balis, D. S.: Solar activity-total column ozone relationships: Observations and model studies with heterogeneous chemistry, J. Geophys. Res., 102, 1561-1569, 1997. 